\title{
Secondary Röntgen Radiation
}

This content has been downloaded from IOPscience. Please scroll down to see the full text. 1906 Proc. Phys. Soc. London 20200

(http://iopscience.iop.org/1478-7814/20/1/313)

View the table of contents for this issue, or go to the journal homepage for more

Download details:

IP Address: 132.239.1.231

This content was downloaded on 05/09/2015 at 05:08

Please note that terms and conditions apply. 
XII. Secondary Röntgen Radiation. By Challes G. Barila, 1.S.Si. (Liverpool), M.Se. (Virtoria), B.A. (King's College, Cambridge); Lecturer in Adeanced Electricity, Vniversity of Liveryool *.

\section{Introduction.}

Since the discorery by Rïntgen of secondary radiation from substances exposed to X-rays, the subject has been investigated by a number of experimenters, including Perrin, Townsend, Dorn, Curie, Sagnac, Langevin, and Bumsteadt.

The results of these investigations have shown that a substance upon which a beam of liöntgen radiation is incident emits two kinds of radiation : an easily absorbed radiation consisting of negatively charged corpuscles or electrons, and a heterogeneous heam of X-radiation differing from the primary in penetrating power. In almost all cases the secondary X-radiation has been found to be more easily alsorbed than the primary producing it; and never has it bren found to possess greater penetrating power. The alsorbability of the radiation from a given substance varies with that of the primary; and probably as a consequence, the results obtained by different experimenters for the relative absorptions of the radiations from different substances do not agree. Recently Bumstead has made experiments from which be concludes that the absurption of a given X-ray beam and the secondary beam arising from it, results in the generation of albout twice as nuch heat when the absorbing and mdiating substance is lead thm when it is zinc.

The writer + investigated the radiation proceeding from ganes and light substances when subject to $X$-rays, and found

* Read February $23,1906$.

+ Perrin, Annules de Chimie et de I'hysique, [7] xi, n. 496 (1897). Townsend, Proc. Canzb. Phil. Soc. x. p. 217 (1899). Dorn, Abhand. $d$. nuturf. Ges. zu Halle, xxii. p. 39 (1900). Sagnac, Annales de Chimie et de Physique, [7] xxii. p. 493 (1901). Curie \& Sagnac, Joumal de 1\%!ysique, [4] i. p. 1:) (1902). Langrerin, Recherches sur les yaz ionisés. Bum.tead, Phil. Mag, xi. pp. 292.317. Feb. 1906.

† Barkla, Phil. Mag. v. pp. 685-698, June 1903 ; vii. pp. 543-560, Mar 1919) 
that the radiation not alsorbed by a few centimetres of air unler ordinary atmospheric conditions differed exceedingly little from the primary. From certain gases and light solids the radiation was found by direct experiment not to differ appreciably in absorbability from the primary; but there was indirect evidence of greater absorbability in air. From these substances the intensity of radiation was found to be proportional to the quantity of matter passed tnrough by the primary radiation of given intensity.

These laws were accounted for by the theory that the corpuscles or electruns constituting the atoms scattered the primary radiation. The intensity of radiation was experimentally investigated, and a close agreement found between that and the result of a calculation hy Prof. J. J. Thomson * when applied to the electrons. The theory was further verified by the discovery of partial polarization in a primary beam proceeding from an X-ray tube, by a study of the iutensity of secondary radiation in different directions, and later by the demonstration of much more complete polarization of secondary radiation proceeding from one of the substances (carbon) to which the theory was supposed applicable $\dagger$.

'Ihese results furnished data and suggested methods for investigating the complex secondary radiations proceeling from metals subject to $\mathrm{X}$-rays more completely than bad previously been attempted.

The experiments described below were made on the more penetrating radiations, that is the radiations which had passed through several centimetres of air under ordinary atmospheric conditions and very thin aluminimm leaf.

Density, Molecular Weight, Atomic Wright of Rudiator.

Preliminary experiments on the absorbalility of the secondary radiation proceeding from different substances when subject to X-rays were made in the manner described in previous papers. It was seen that in general light substances emitted radiations differirg very little in this

* J. J. Thomsnn. 'Cenduction of Jilectricity through Gases,' 1. 2.70.

† Barkla, Phil. T'rans. A, vol. 204 (1605) pp. 46i-4i9; I'ruc. Riny. Soc. A. rol. lxxrii. pp. 24i-25i (190t). 
respect from the primay producing them, while from leary substances the radiation was more easily alsorbed. Whether the character depended on density, molecular weights, or atomic weight had to be investigated.

The gases hydrogen, air, sulphurettred lydrogen, carbon dioxide, and sulphur dioxide had all heen foumd to emit raliation closely resembling the primary. Carbon, paper, wood, and even aluminium and sulphnr, were found to emit radiations differing comparatively little from the radiation producing them; while calcium, iron, copper, zinc, tin, platinum, and lead emitted radiations of considerably less penetrating power than the primary producing them.

It should be olserved that this is only a general way of classifying the radiations enitted by different substances; for upon clo-e examination it was concluded that in all cases there was a difference between the primary and secondary mrs. The difference was, howerer, so smill in many ensesincluding those in which aluminium and sulphur were the radiators-in comparison with that when one of the second class of substances was experimented upon, that these substances may be conveniently proken of as scattering and transforming the radiations*.

The compounds ammonium carbonate, lime, calcium carbonate, and copper sulphate were afterwards tested. Ammonium carbonate was found to emit a radiation closely resembling the primary, and the others radiutions much more absorbable than the primary. Thus ammonium carbonate, a substance of greater molecular weight than calcium or lime, belonged to what may lie called the scattering class, while calcium and lime were among the transforming substances. Aluminim also bulonged to the former class, while calcium, at substance of less density, belonged to the latter.

On the other hand, all the elements in the former class hanl atrmic weights lower than any in the latter class, and the radiation proceding frum a compound was such as would be obtained by a mixtme of the radiations proceeding from the ennstituent elements.

These experimenti indicated that the chatucter of secondary

* Futher tenson fur this classification is oiven later. 
radiation set up by a given primary depends upon the atoms subject to that radiation, and not to any great extent, if at all, on their distances apart or on their combination with atoms of other substances.

\section{Absence of Purely Scattered Riadiution.}

In further investigating the secondary rays from surstances of higher atomic weight, experiments were marle to ascertain if the radiation consisted of a radiation such as was found to proceed from substances of lower atomic weight superposed on a more easily absorbed raliation.

The radiation from tin when placed in the primary beam was studied by the method described in a previous paper. The absorbability of the radiation was measured by placing successive laver of thin aluminium in front of the electroscope through which the secondary heam passed. The ionization was initially large; but as sheet after sheet of aluminium was placed in the path of the secondary radiation, the reduction was so great that the resultant ionization produced in the secondary electroscope was found to be much less than what would have resulted if simple scattering had occurred in the tin sach as was found in substances of low atomic weight. That is, taking account of the absorption of the primary beam in the plate of tin and of the secondary in the same plate and in the aluminium absorbing plates, if the same percentage had been scattered as was found from light atoms, a much greater ionization would have been produced than was actually measured. The absorptions of primary and secondary rays were determined by separate experiment. Thus the secondary radiation was found to consist almost entirely, if not entirely, of a completely transformed radiation.

\section{Temperature, Electric Conductirity, Iugnetic Permealility.}

To determine if the character of secondars radiation was in any way connected with the temperature, electric conductivity, or magnetic property of the radiator, a grating was made of iron wire in the form of a bolometer-grating, and was exposed to primary X-rays just as sheets of metal had

rOL. $x x$. 
heen. The ionization produced in the electroscone was considerable on account of the great absorbability of the secondary rays. A current was then passed through the wire grating till it became almost "white hot." It was seen that though very flexible, it was no longer deflected under the action of a strong magnet placed near. With this great rise of temperature, consequent increase of resistance and disappearance of magnetic property, no change was observed in the ionization produced by the secondary beam, though a change in intensity or absorbubility of the radiation by 2 or 3 per cent. would have been detected.

Thus there was no appreciable direct connexion between the character of the radiation and the temperature, conductivity, or magnetic permealility of the radiating substance.

The observations were taken in the order shown below, the experiments heing made with the wire alternately hot and cold.

\begin{tabular}{|c|c|c|}
\hline State of Raclintor. & & $\begin{array}{l}\text { ings and Deflexion } \\
\text { of Electroscope } \\
\text { per minute. }\end{array}$ \\
\hline Hot & & $\left.\begin{array}{l}40 \cdot 4 \\
66.5\end{array}\right\} 26 \cdot 1$ \\
\hline Cold & & $\left.\begin{array}{l}41 \cdot 7 \\
68.7\end{array}\right\} 27$ \\
\hline Hot & & $\left.\begin{array}{l}41.5 \\
60.5\end{array}\right\} 28$ \\
\hline cold & ,......... & $\left.\begin{array}{l}40.2 \\
70.1\end{array}\right\} 29.9$ \\
\hline
\end{tabular}

Solectire Alsorpition.

It has been stated by experimenters that the radiation proceeding from a heary metal is more easily absorbed by that metal than would be expected by comparing the absorbabilities of other rays in different substances; that is, that the rays are specially absorbed by the metal from which they are cmitted. If this were so, it would indicate a more or less dufinite period of vibration of corpuscles or clectrons in a given substance producing a radiation having some of the properties of Röntgen radiation; also that this vibration is set up by the passage of X-rays throngh the substance. 
Experiments were made to verify this important conclusion if possible, and to learn the extent of this special absorption. A comparison of the absorbability of the secondary rays from lead in aluminium and in tin was made. (The secondary rays studied passed through about $11 \mathrm{~cm}$. of air at atmospheric pressure before passing through the absorbing plates into the electroscope. This distance was chosen becnuse the rays previously experimented upon had travelled an equal distance from the radiator.) Then the absorptions of the secondary rays from tin in aluminium and tin were determined. Absorbing plates of thickness to diminish the ionization by approximately the same amount were used. It was found that the ratio of the two absorptions by aluminium and tin for the radiation from lead was, within a small possible error, the same as that ratio when the radiation from tin was absorbed.

No evidence then of special absorption for the radiation from tin by tin was obtained.

\section{Variation in Intensity of Primary Radiation.}

Experiments were made to determine the effect on the secondary raciation of variation in intensity of the primary. Calcium was chosen as the radiating substance, because it was the substance of lowest atomic weight experimented upon which emitted a radiation differing considerably from the primary, and consequently might be expected to be specially sensitive to such variations. The apparatus used in these experiments was that described in previous papers on polarized Röntgen radiation. The electroscope receiving the vertical secondary beam was used to standardize the intensity of the horizontal secondary beam, while plates of aluminium were placed in the path of the latter to the electroscope.

The ratio of the rates of deflexion of the two electroscopes appeared constant under definite controllable conditions, so no particular period of discharge was taken. Variation in intensity of the primary was obtained by varying the distance of the X-ray tube from the calcium radiator. 
The results are given below :-

\begin{tabular}{|c|c|c|c|c|}
\hline Conditions. & $\begin{array}{c}\text { Distance of } \\
\text { Anticathode } \\
\text { of X-ray tube } \\
\text { frow } \\
\text { Radiator. }\end{array}$ & $\begin{array}{l}\text { Deflexion of } \\
\text { Upper } \\
\text { Electroscope } \\
\text { (standard). }\end{array}$ & $\begin{array}{l}\text { Deflexion of } \\
\text { Lowe' } \\
\text { Electroscope. }\end{array}$ & $\begin{array}{l}\text { Ratio of } \\
\text { Deflexions. }\end{array}$ \\
\hline $\begin{array}{l}\text { No absorbing plate ...... } \\
\text { Aluminium plato }(01 \mathrm{~cm} .\end{array}$ & 28 centius. & $\left.\begin{array}{l}44 \cdot 8 \\
54 \cdot 3\end{array}\right\} 9 \cdot 5$ & $\left.\begin{array}{l}16 \cdot 8 \\
32 \cdot 4\end{array}\right\} 15 \cdot 6$ & 10 to 16.4 \\
\hline $\begin{array}{l}\text { thick) before lower } \\
\text { electroscope }\end{array}$ & 28 & $\left.\begin{array}{l}55 \cdot 4 \\
70 \cdot 0\end{array}\right\} 14 \cdot 6$ & $\left.\begin{array}{l}34 \cdot 8 \\
42 \cdot 4\end{array}\right\} 7 \cdot 6$ & 10 to $5 \cdot 2$ \\
\hline$" \quad n \quad \ldots$ & 78 & $\left.\begin{array}{l}49 \cdot 2 \\
66 \cdot 2\end{array}\right\} 17$ & $\left.\begin{array}{l}18 \cdot 8 \\
27 \cdot 3\end{array}\right\} 8 \cdot 5$ & 10 to 5 \\
\hline No absorbing plate ...... & 78 & $\left.\begin{array}{l}65 \cdot 3 \\
77 \cdot 4\end{array}\right\} 12 \cdot 1$ & $\left.\begin{array}{l}25 \cdot 8 \\
46 \cdot 0\end{array}\right\} 20 \cdot 2$ & 10 to $16 \cdot 7$ \\
\hline
\end{tabular}

From these we see that the ionization produced by the secondary radiation from the intense primary beam was reduced by 68.3 per cent. of its original value, while that produced by the secondary radiation set up by the weak primary beam was diminished by 70 per cent.

The difference between these was within the limits of possible error of experiment. We thus see that the cbaracter of the secondary radiation from calcium did not depend to any appreciable extent on the intensity of the primary.

Similar experiments were made when iron was used as the radiating substance. The sheet of aluminium when placed in the path of the secondary bean diminished its ionizing effect in successive experiments by $90 \cdot 6$ per cent., $90 \cdot 9$ per cent., 90.9 per cent., and 90.5 per cent. In the first experiment the radiation emitted by the tuhe was very weak. Before the second the tribe was heated, consequently it worked much more easily and produced a very much greater ionization. For the third it was removed to something like double the distance from the iron radiator, and for the fourth it was brought back. The variation in absorption as shown by the above numbers must have been exceedingly small, if it existed at all.

Experiments have been made at different times to determine if the intensity of secondary radiation was proportional to that of the primary. In all cases so far investigated, the proportionality has been demonstrated within two or three per cent. 
Variation in Penetrating Power of the Primary Radiation.

It was of interest to determine in what way and to what extent the secondary radiation from a particular substance depended on the character of the primary radiation. Fr rom substances of low atomic weight it had been seen that the character was dependent solely, or almost solely, on that of the primary and to an inappreciable extent on the nature of the radiator.

It was found that as the difference in character between the secondary and primary rays became more marked by increasing the atomic weight of the radiator, the effect on the secondary of a change in character of the primary diminished.

From those substances which emitted a radiation varying in intensity in different directions when the primary beam was polarized, there were considerable variations in absorbability, the secondary becoming more penetrating as the primary became more penetrating. The radiation from those substances, however, which produced considerable transformation and which gave no evidence of polarization of the primary beam, was extremely little affected by considerable changes in the character of the primary, though in all cases it appeared slightly more penetrating when a penetrating primary beam was used. The change was remarkably small in some cases.

The slight change in the charncter of the secondary radiation from copper when the primary was changed is shown by the following results.

The absorption of the secondary beam from copper by a plate of aluminium $01 \mathrm{~cm}$. in thickness, when the primary beam came direct from an X-ray tube, was found to be 72.75 per cent. When only the penetrating portion of the primary which had got through an aluminium plate $079 \mathrm{~cm}$. thick was used as the primary beam, the absorption of the secondary was found to be 71.8 per cent. Now the former primary beam used was found to be absorbed to the extent of about 35 per cent. by the same plate of aluminium, whereas the second primary beam was absorbed by only 10 or 12 per cent.

But by placing the altuminium plate $.079 \mathrm{~cm}$. thick in the 
primary beam before it fell on the radintor of copper, the ionization produced by the primary was reduced to 14 per cent., and that by the secondary to 19 per cent. of the original ionizations.

We thus see that thongh 81 jer cent. of the secondary ionization was produced by the secondary rays set up by the absorbable portion of the primary beam, yet when this was cut off the enormously more penetrating portion of the primary set up secondary rays differing in absorbability by something of the order of 1 per cent.

When iron was used as the radiator, the change in character was still less, the absorption of the secondary set up by the primary beam direct from the bulb being $90 \cdot 6$ per cent., 90.9 per cent., 90.9 per cent., and 90.5 per cent. in successive experiments; while it was 90.2 per cent. and 90 per cent. when the thick aluminium plate was placed in the primary beam.

The absorption of the radiation from lead appeared much more variable. From sereral experiments the absorption of the secondary leams set up in the same way in lead as in the two experiments on copper, were found to be about 39 per cent. and 35 per cent., indicating a greater dependence on the character of the primary.

As a general rule, it was also found that experiments on those substances which emitted a very easily absorbed radiation gave much more constant results than those on substances emitting a comparatively penetrating radiation.

It is, however, important to notice the effect of heterogeneity in both primary and secondary beams, assuming the character of the secondary radiation to be independent of that of the primary. First dealing with those substances which emit a radiation of fair penetrating power, as silver, cadmium, and tin, the layer of metal from which the secondary rays proceed has a thickness comparable to that penetrated by the primary rays. Consequently, when a more penetrating primary beam is used, a greater proportion of the secondary radiation proceeds from the deeper layers, and in its passage to the surface of the metal is robbed of its more absorbable constituents. On the whole, then, the emergent secondury beam consists of a larger proportion of penetrating rays than 
when set up by a more easily absorbed radiation. On the other hand, when the secondary radiation is very easily absorbed, as in the case of the radiation from iron, the layer from which secondary rays emerge is very thin, and variation in the penetrating power of the primary does not appreciably change the thickness, all the primary rays getting through with little diminution in intensity. Hence, whether penetrating or comparatively absorbable rays form the primary, the emergent secondary is from the same thickness of metal, and is therefore equally penetrating.

It appears possible then that this alone would account for the differences observed and given in detail above. But there

Fig. 1.

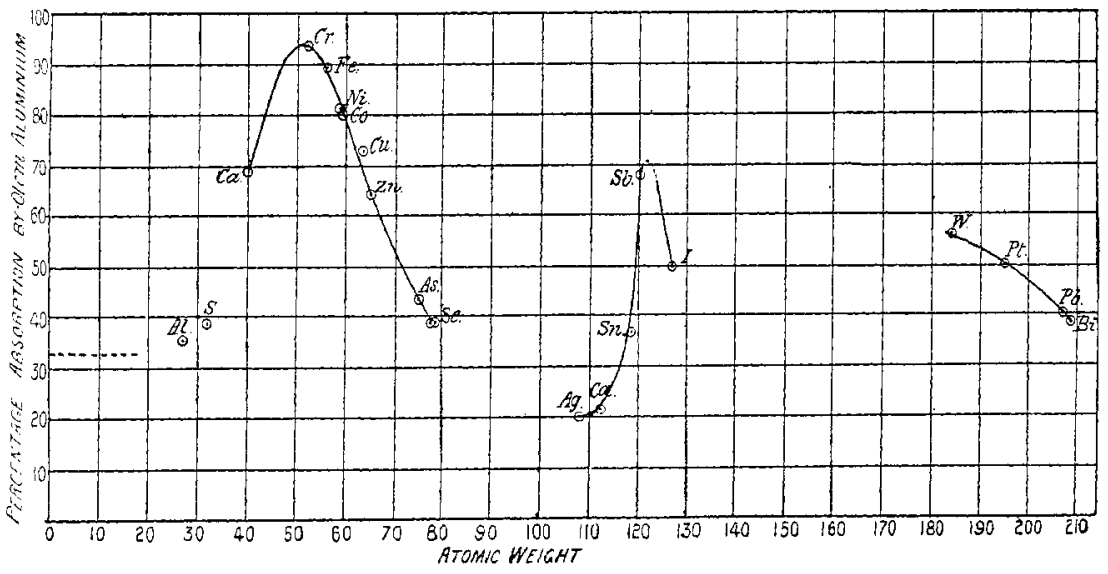

were found to be enormous changes in the absorbability of the secondary rays from antimony and iodine, for instance, due to changes in the primary radiation, though the absorption of some of these beams was greater than that of some secondary radiations whose character appeared very constant when that of the primary was varied.

In general the substances from silver to iodine (see fig. 1) emitted secondary rays showing remarkable variations in absorbability in different experiments. The behaviour of these substances and of those in the middle of the first long chemical period form a striking contrast.

This points to the conclusion, though the evidence is 
not decisive, that at least some substances emit a radiation differing considerably in absorbability from the primary, and exhibiting considerable variation in character as the primary is varied.

[Note, May 14th, 1906.-More recent experiments with thin metal leaves have shown this conclusively.]

\section{Polarization.}

Further information regarding the nature and cause of the radiation was obtained by using a partially polarized beam of $\mathrm{X}$-radiation for the primary, and measuring the intensity of radiation proceeding in different directions from the substances investigated. It was shown in the paper on "Polarized Röntgen Radiation," that from those sulstances, in which, during the passage of a Röntgen pulse, the corpuscles or electrons are accelerated in the direction of electric displacement, the secondary radiation differs in intensity in different directions, giving evidence of the polarization in the primary beam. These substances are also the origin of polarized secondary radiation. When the acceleration of electrons ceases to be in the same direction as the electric displacement in the primary pulse, evidence of polarization of the primary disappears, and the secondary radiation ceases to be polarized. Conversely, the disappearance of evidence of polarization, i.e. of the variation of intensity of secondary radiation in different directions at right angles to the primary, when polarization has been demonstrated, show's that the secondary radiation ceases to be polarized and that the electrons cannot now be accelerated in the direction of electric displacement during the passage of Röntgen pulses.

To test the nature of the secondary pulses from this point of view, experiments were made using different substances as radiators, and it was found that approximately equal evidence of polarization was given by all those substances of low atomic weight which emitted a radiation whose character differed little from the prinary; that with those substances of lowest atomic weight which were the source of a secondary radiation differing to a greater extent from the primary, polarization was shown to a smaller extent; and all substances 
experimented upon with atumic weights beyond a certain value gave no evidence of polarization at all. Thus carbon, air, cardboard, aluminium, and sulphur emitted a secondary radiation, varying in intensity in the principal directions by about the same amount. Calcium emitted radiation exhibiting about half this variation, while the radiations from iron, copper, zinc, tin, and lead exhibited no rariation at all. Thus the character of the pulses changed not abruptly with an increase in atomic weight, but very rapidly between certain atomic weights.

It is significant that the polarization effect disappears with the similarity between the secondary and primary radiations. We thus see that the change in absorbability of the secondary radiation is accompanied by an acceleration of electrons in directions not those of electric displacement in the pulses producing the radiation. This is importint, because the difference in character between the primary and secondary radiations might possibly be accounted for by a change in the average distance apart of the separate pulses. Here, however, we see that the change in character is accompanied by a change in what might be called the pulse structure. The rather striking independence of the absorbability and the distances of the pulses apart is shown in the case of secondary radiation from a mass of carbon for instance; for on the theory of the production of secondary radiation, each electron is the source of a secondary pulse, yet in spite of tbis enormous multiplication of pulses, the absorption of the radiation differs very little from that of the primury.

The componnds ammonium carbonate, lime, calcium carbonate, and copper sulphate were tested in the same manner. Ammonium carbonate emitted a radiation varying in intensity in the principal directions by about the same amount as that shown by the elements of low atomic weight. Lime and calcium carbonate emitted radiations showing a smaller variation, while from copper sulphate evidence of polarization of the primary could not be detected.

These results again are what would he given by mixtures of the radiations proceeding from the different constituents. All the elements in ammonium carbonate belong to the scattering class, and hence the full variation is produced. In 
the racliations from calcium oxide and calcium cabonate, the rays from calcium produce most of the ionization on account of its greater absorbability, and hence little more than half the full variation was found, the rays from calcium itself showing only about half the variation shown by those from lighter elements.

In the radiation from copper sulphate, the rays from copper were so ensily absorbed that the effect of the more penetrating rays from sulphur and oxygen was swamped, and no evidence of rariation in intensity in different directions was detected.

Experiments were also made to ascertain if the more penetrating portion of the secondary radiation from some of the heavier sulustances gave evidence of polarization in the primary; for if the character of the radiation depended on the relation between the pulse-thickness and the distances separating the electrons, we might expect that the effect of thin pulses passing through a heavy atom would be similar to thicker pulses passing through an atom in which the electrons are not so closely packed.

No such evidence was obtained (sce paper on "Polarized Röntgen Radiation").

[These experiments on polarization were made before the absorbability of the rays from many substanees had been determined. It will be interesting to learn if evidence of polarization renppears when such a substance as silver is used as the radiator (see fig. 1). The radiation from silver, however, is much more absorbable than the primary producing it, though from a thick plate its ionizing effect is diminished by a smaller fraction than that of the primary by passage through a thin plate of aluminium. Enormous differences are observed in the character of the radiations proceeding from thin and thick plates of the same substance.]

\section{Connevion letween Atomic Weight of Radiating Substance and Character of Secondury Radiation.}

Though it is impossible to determine the true character of the radiation as it proceeds from an atom of the radiating substance except by using very thin plates, it was thought 
that by using plates of sufficient thickness to absorb nearly all the incident primary radiation, or rather that portion of it which produced an appreciable effect in the electroscope, some law might be found to exist where from a few isolated results there appeared to be great irregularity.

A large number of elements were therefore in turn exposed to the primary radiation, and the penetrating power of the rays from each was observed.

The experiment was simply the following:-

The rates of leak of an electroscope receiving a narrow pencil of primary radiation and of one receiving a beam of secondary radiation from the substance experimented upon, were observed when no absorbing plates intercepted the radiations. A plate of aluminiun $.01 \mathrm{~cm}$. in thickness was placed in front of the electroscope receiving the secondary beam, and the two rates of deflexion of the gold-lenves were again observed. The percentage reduction of the ionization in the secondary electroscope was found, using the electroscope receiving the pencil of primary radiation to standardize the intensity of the primary. (In some cases an electroscope receiving a secondary beam was used to standardize the intensity.)

In these experiments, no particular care was taken to keep the character of the primary radiation constant; but in one or two cases several experiments were made on a pair of metals talien alternately, Bismuth and lead, silver and cadmium were trented in this way. Consequently the results can only be regarded as approximately true, and little value is attached to the absolute absorptions obtained, for under certain conditions some of the elements were found later to give results differing considerably from these. The most variable were those from silver to iodine (fig. 1). There was, bowever, no indication of much variation in the majority of cases. The elements were studied irregularly, and the discharge in the X-ray tube was not kept more constant than could be done by ordinary observation. The results, though incomplete, and possibly containing one or two errors in detail, are, I think, of sufficient interest to justify their publication at this stage of the investigntion.

They also suggest a method of determining atomic weights 
by interpolation, for a small variation in atomic weight is usually accompanied by a very considerable change in absorbability of the secondary radiation. It appears probable that a variation of atomic weight by one fourth in certain regions would be detected, but the possible error varies considerably from one region to another.

\begin{tabular}{|c|c|c|}
\hline Substance. & Atomic Weight. & $\begin{array}{l}\text { Percentage 'A bsorption' * } \\
\text { by '0l em. Aluninium. }\end{array}$ \\
\hline Aluminium & $27 \cdot 1$ & $35 \cdot 5$ \\
\hline Sulphur & $32 \cdot 06$ & 39 \\
\hline Calcium & $40 \cdot 1$ & 69 \\
\hline Chromium & $52 \cdot 1$ & $93 \cdot 5$ \\
\hline Iron ..... & 55.6 & 89 \\
\hline Nickel .. & $58 \cdot 7$ & 81.5 \\
\hline Cobalt .. & $50 \cdot 0$ & 80 \\
\hline Copper.. & $63 \cdot 6$ & 73 \\
\hline Zine.... & $65 \cdot 4$ & 645 \\
\hline Arsenic & $75 \cdot 0$ & $43 \cdot \overline{5}$ \\
\hline Selenium & $79 \cdot 1$ & 39 \\
\hline Silver ........ & 107.9 & 20 \\
\hline Cadmium .......... & $112 \cdot 4$ & $21 \cdot 5$ \\
\hline $\operatorname{tin} \ldots \ldots \ldots$ & $118 \cdot 5$ & 36.8 \\
\hline Antimony.......... & $120 \cdot 0$ & 68 \\
\hline Iodine $\ldots \ldots$ & $127 \cdot 0$ & 50 \\
\hline Tungsten .... & $184 \cdot 0$ & 56 \\
\hline Platinum & $194 \cdot 8$ & 50 \\
\hline Lead.... & $206 \cdot 9$ & 40 \\
\hline Bismuth ... & $208 \cdot 5$ & $38 \cdot 5$ \\
\hline
\end{tabular}

Percentago 'absorption' of the primary was about 33 .

* As mensured by diminution of ionization in an electroscope.

It would be useless to attempt to calculate from these results absorption coefficients for the different radiations, for the primary and secondary beams consist of mixtures of ruys differing enormously in penetrating power, and these constituents produce effects in the electroscope which cannot even be regarded as approximately proportional to their energies. Also the constituent of the primary beam that sets up in one metal the most effective constituent in the secondary beam, is not that which gives rise to the most effective constituent in another metal; so that the ionizations produced in the electroscope receiving the secondary beam are not strictly due to the same primary beam.

The absorption of a given radiation, however, is not a 
periodic function of the atomic weight * , so that the general features of the curve (see fig. 1, p. 209) showing the relation between percentage diminution of the ionization froduced by the secondary beam when a plate of aluminium $01 \mathrm{~cm}$. thick was placed in its path to the electroscope, and the atomic weight of the substance emitting that radiation, are no less significant. The diminution of the ionization by this plate has been spoken of as the "absorption," but this must not be taken as signifying the percentage diminution of energy in the bean traversing the plate.

It will be seen that as far as these experiments have gone, curves showing a rise and fall in the absorption of the secondary radiation connect the absorption and atomic weights of elements in the first and part of the second long chemical periods, and that the latter part of such a curve has been obtained with the latter part of the third long period. These are the periods shown by McClelland $\dagger$, by experiments on the secondary riys from substances subject to $\beta$ and $\gamma$ rays from radium. His curves also show the second short period. The results obtained in these experiments from substances of atomic weights less than 32 have not been plotted, because they were made under different conditions, the radiating layer of gas absorling only a very small fraction of the incident primary radiation. These substances were found to emit rays differing little in character from the primary.

It will be noticed that some substances emitted a radiation whose ionizing effects were diminished more by an absorbing plate than were those of the direct primary beam. The rays, however, were produced by the penetrating portion of the primary beam, so the transformation was one to greater absorbability. This was seen by placing aluminium screens in the primary beam before it fell on the raliating substance,

* What has been proved for primary radjation from an X-ray tube is here assumed for secondary radiations, viz, that there is not selective absorption, the absorption by a given mass being a steadily increasing function of the atomic weight of the absorbing substance. This will be thoroughly tested by obtaining curves similar to that shown in fig, 1, when the aluminium absorbing plate is replaced by other metals.

+ Transactions of Royal Dublin Society, May 17, 1905. 
for the diminution of the secondary ionization was considerably less than when the same screen was placed in the path of the secondary beam. The reason for this is obvious when we consider the different penetrating powers of the constituents of the primary beam.

[Later experiments have shown that variations in the primary beam have such an enormous effect on the character of the radiations from the substances referred to as being inconstant, that the relative positions of antimony and iodine may have to be reversed. The values first obtained with an approximately constant primary beam are, however, unaltered in this paper, as the true positions are not known with certainty.]

\section{Theory.}

The theory which has been shown to account for the phenomena of secondary radiation from certain gases and light solids may be extended to explain the results of esperiments on metals.

In light atoms the corjuscles or electrons have sufficient freedom to move almost entirely independently of each other under the influence of the primary pulses, consequently to emit a radiation whose penetrating power is the same as that of the primary, and whose intensity depends on the direction of propagation with regard to the plane of polarization in the primary beam.

In heavier atoms each electron is more intimately connected with the electrons in its immediate neighbourhood, and is therefore subject to considerable disturbing forces due to the displacement of these. The period for which it is subject to considerable forces is much greater than that of passage of the primary pulse over it, hence the secondary pulse emitted is thicker and more complex in character. The greater thickness of the secondary pulse results in greater alsorbability; and the interference with the simple direct acceleration due to the primary pulse prevents pure scattering, and ascounts for the disappearance of polarization in the secondary beam and of evidence of polarization in the primary. An increase in thickness of the primary pulse produces an increase in thickness of the secondary pulses; 
consequently an increase in absorbability of the primary results in an increase in the absorbability of the secondary.

On this hypothesis, the penetrating power of the secondary radiation is a measure of the independence of motion of corpuscles or electrons within the atom; and the relation between absorption and atomic weight exhibiting a periodicity which is obviously connected with the periodicity in chemical properties, is evidence of a connexion between chemical properties and distribution of corpuscles in the atom such as Prof. J. J. Thomson suggests.

It would be premature at this stage of the investigation to attempt a more detailed explanation of the results, as the experimonts are still very far from completion.

The theory, however, appears sufficient to explain the results of experiments made up to the time of writing, without assuming apprecialule disintegration of the atom to oceur. Radiation due to disintegration may or may not form a portion of the secondary radiation emitted by metals and detected by means of an electroscope, but it appears probable that the radiations studied lave been at the expense of the energy of primary radiation.

It should perhaps be recalled that strong evidence of the similarity in nature of the secondary radiation from copper (a substance emitting a radiation differing considerably in alsorbability from the primary producing it) was given in a previous paper".

The energy of secondany radiation from light atoms was shown to be accounted for by scattering of the primary radiation by the constituent electrons.

From calcium a radiation differing considerably from the primary was prodneed exhibiting, to a certain extent, the polarization in the primary beam. From tin the purely scattered radiation was entirely or almost entircly absent.

Now it cannot be supposed that more than an exceedingly small fraction of the coryuscles were displaced sufficiently to disturb the stability of the atom; hence the disappearance of the scattered radiation was not due to any instability during the passage of the primary julses.

The disappearance of scattering and the appearance of an

* Plil, Mrag, vii, pp, 543-560, May 100t. 
easily absorbed radiation together point to the same cause, and as all the observed effects may be accounted for by this, it is improbable that an appreciable disintegration sets in at the same atomic weight.

Also if the energy of secondary radiation depen led on there being sufficient electric intensity in the primary pulses to produce disintegration of the atom, we should have to conclude, as we find intensity of secondary radiation proportional to the ionization produced by the primary in the primary electroscope (the character remaining constant), that the disintegration produced in a given metal by a primary beam is proportional to the ionzation produced in a given gas by the same beam.

If we apply the disintegration theory to calcium, we must conclude that the scattered radiation and the radiation due to disintegration are in a constant proportion whatever be the intensity of the primary, for the absorbability of the mixture is unchanged. This appears very improbable.

Again, the change in character of the secondary with that of the primary indicates that a considerable portion at least of the secondary radiation is not due to disintegration, for the charncter of this we should expect to be independent of the exciting cause and to be characteristic merely of the atom.

It is significant also that the secondary rays have been invariably found to be less penetrating (yet not of an entirely different order of magnitude) than the primary producing them; a result necessary to the theory here given, and not at all likcly on the disintegration theory.

If Prof. Bumstead's conclusions on the point are correct, it appears probable that investigations on the easily ahsorbed radiation would throw further light on the subject. I hope to make such investigations shortly.

In conclusion I wish to express my indebtedness to $\mathrm{Mr}$. C. A. Sadler, B.Sc., and Mr. A. I. Hughes, for their valuable assistance in conducting some of these experiments.

George Folt Physics Laboratory, Liverpool. 